Research Article

\title{
Design of Curcumin-Loaded Electrospun Polyhydroxybutyrate Mat as a Wound Healing Material
}

\author{
Reyhaneh Ghavami L ${ }^{1}$, Esmaeil Biazar ${ }^{1}$, Arezoo Sodagar Taleghani ${ }^{2}$, Saeed Heidari Keshel ${ }^{3}$ \\ ${ }^{1}$ Department of Biomaterials Engineering, Tonekabon Branch, Islamic Azad University, Tonekabon, Iran. \\ ${ }^{2}$ Department of Chemical Engineering, Science and Research Branch, Islamic Azad University, Tehran, Iran. \\ ${ }^{3}$ Department of Tissue Engineering and Applied Cell Sciences, School of Advanced Technologies in Medicine, Shahid Beheshti \\ University of Medical Sciences, Tehran, Iran.
}

Corresponding author. E-mail: kia_esm@yahoo,com Tel.: +98 1924271105 Fax: +98 1924274415

Received: Oct. 16, 2019; Accepted: Feb. 7, 2020; Published: Feb. 13, 2020.

Citation: Reyhaneh Ghavami L, Esmaeil Biazar, Arezoo Sodagar Taleghani, and Saeed Heidari Keshel, Design of Curcumin-Loaded Electrospun Polyhydroxybutyrate Mat as a Wound Healing Material. Nano Biomed. Eng., 2020, I2(I): 14-20.

DOI: $10.5101 /$ nbe.v12i1.p14-20.

\begin{abstract}
Nanotechnology and tissue engineering have accelerated wound healing. Polyhydroxyalkanoates, with suitable physical, biological and mechanical properties, can be considered as a good candidate in tissue repair and regeneration. In this study, nanofibrous mats of polyhydroxybutyrate (PHB) containing curcumin as a wound healing agent, were designed by electrospinning method. The samples were evaluated by microscopic and mechanical analyses, cell assays and microbial tests. The results of microscopic images showed that the diameter of fibers increased with the increase in the curcumin concentration. The elongation and elasticity modulus of nanofibers increased and decreased respectively, with the increase in the amount of curcumin. Drug release study indicated that increasing the curcumin concentration into nanofibers accelerated rate of drug release. Cytotoxicity results of nanofibrous samples with lower curcumin showed better biocompatibility. The strongest antibacterial activity was shown by the sample with $3 \%$ curcumin. In addition, Curcumin-loaded nanofibrous PHB can be potential candidates for wound healing.
\end{abstract}

Keywords: Controlled release; Curcumin; Cytotoxicity study; Physical and mechanical properties; Polyhydroxybutyrate (PHB) nanofiber

\section{Introduction}

Tissue engineering is a multi-disciplinary field that uses the principles of biology as well as engineering to develop biological alternatives by repairing, rebuilding, and enhancing or maintaining tissues operations $[1,2]$. Creation of a three-dimensional scaffold which has suitable properties such as high porosity, interconnected pores, and high degradation rate is one of the key factors of tissue engineering. Biodegradable polymeric scaffolds can typically be fabricated by different methods $[3,4]$. In natural tissues, extracellular matrixes which have physical structures ranging from nanometer to micrometer scale. For this reason, a nanostructured porous material with a high surface area is as an alternative for destroyed extracellular matrixes (ECMs). Many researchers have attempted to fabricate nanofibrous structures [5] like electrospinning method [6-18] to mimic the natural ECM scaffold. A wide variety of natural and synthetic biomaterials, such as glycosaminoglycans (GAGs), collagen, hyaluronic acid (HA), fibrin, polycaprolactone (PCL) and polyglactin 
have been used to fabricate scaffolds for wound healing [19-22]. Polyhydroxyalkanoates (PHA) are a class of aliphatic polyesters, produced by bacteria during unbalanced growth conditions. PHAs are attractive biomaterials for tissue engineering applications due to their excellent biocompatibility and biodegradability properties [15, 23-29]. Curcumin (Cur) is the main active compound of turmeric, which is acquired from the rhizomes of the herb (Curcuma longa L.) and has been used for centuries as a natural dye in the food as well as traditional medicine, particularly in South and Southeast Asia [30]. Curcumin has antitumor, antiinflammatory, and antioxidant properties. Moreover, due to favourable pharmacological properties of curcumin, it has a remarkable potential in biomedical applications such as wound healing, radio-sensitizing, and chemo-sensitizing [31, 32]. However, many studies have reported that the bioavailability and therapeutic efficiency of curcumin is limited due to its poor water solubility. As many studies have suggested, the efficiency of scaffolds in tissue regeneration can be increased by using curcumin as an antiinflammatory agent and cellular stimulus [33-35]. In this study, polyhydroxybutyrate (PHB) nanofibrous mats containing curcumin with different concentrations were designed using electrospinning technique, and their suitability for wound healing was evaluated by mechanical, morphological, and microbial and cellular tests and drug release study.

\section{Experimental}

Poly-[3-hydroxybutyrate] (PHB) and solvents (chloroform, and dimethylformamide (DMF)) for preparing PHB solution were purchased from SigmaAldrich (St Louis, MO, USA) and used without further purification. Electrospinning apparatus used in this study prepared from Nanoazma Company (Tehran, Iran). For preparing electrospinning solutions, the PHB polymer and curcumin with different concentrations were dissolved in chloroform and DMF at the ratio of 70 : 30, by stirring for 4 hours (at $60{ }^{\circ} \mathrm{C}, 1250 \mathrm{rpm}$ ). A high-voltage power supply through a wire was used at the tip of a syringe needle. A strong electrical field was created between the polymer solution and a collector. With increasing voltage, once the electric field attained a certain critical value, the repulsive electric force overcame the surface tension of PHB solution and a charged jet of solution was ejected from the tip of the Taylor cone. Ultrafine fibres were formed as the ejected jet fluid was narrowed by increasing the net charge density due to evaporation of the solvent. An electro spun PHB nanofibrous mat was carefully detached from the collector. In order to remove solvent molecules completely, it dried in vacuum for 2 days at room temperature.

\section{Morphology of curcumin-loaded PHB nanofibers}

The surface morphology and the fiber diameter of electrospun PHB and curcumin-loaded PHB nanofibers were studied using a scanning electron microscope (Cambridge Stereo-scan, S-360, Wetzlar, Germany) (SEM) at various magnifications. Initially, the samples were placed on SEM specimen stubs, and then the surface of them was coated with a thin layer of Au-Pd using the sputtering device under an argon atmosphere to obtain electrically conductive surfaces. The fiber diameter was measured from different locations. The Image $\mathrm{J}$ software was used to analyse the average fiber diameter of PHB and curcumin-loaded PHB nanofibers.

\section{Mechanical analysis}

Samples (length: $6 \mathrm{~cm}$, and width: $0.3 \mathrm{~mm}$ ) were analysed by a mechanical testing machine (Santam Co.Ltd, Iran) at a speed of $3 \mathrm{~mm} / \mathrm{min}$ to investigate the mechanical properties of nanofibrous mats. Tests were conducted at $25^{\circ} \mathrm{C}$ and humidity conditions of $50 \%$. All data were expressed as the mean \pm SD. The data were subjected to statistical analysis (t-test). Probability values for the significance of differences between values were calculated, and $P$ values of less than 0.05 considered significant.

\section{In-vitro curcumin release studies}

For the curcumin release study, a calibration curve for PBS was plotted. First, a known amount of curcumin in PBS was added and mixed well. Then, the solution was diluted in different proportions to obtain solutions with certain concentrations of curcumin. The maximum absorption spectrum of curcumin is $426 \mathrm{~nm}$. A piece of nanofibrous samples $\left(1 \mathrm{~cm}^{2}\right)$ containing $1 \%$ and 3\% curcumin were cut into PBS buffer in a shaker incubator $\left(120 \mathrm{rpm}\right.$, at $\left.37{ }^{\circ} \mathrm{C}\right)$. At the predetermined time intervals, $2 \mathrm{~mL}$ of the solution was removed and replaced immediately with an equivalent volume of fresh medium to keep the volume constant. The amount of curcumin in the sample solution was determined spectrophotometrically using absorbance measurement at $426 \mathrm{~nm}$. The drug release percentage can be obtained 
using the following equation:

Drug release $(\%)=\left(M_{t} / M_{n}\right) \times 100$

where is the amount of drug released at time $t$, and is the amount of drug loaded in polymer nanoparticles of PHB.

\section{Cell culture}

Isolation and culture protocol of the ADSCs was previously described by Kogler et al. [36]. Cell viability and proliferation were analysed with the tetrazolium salt 3-(4,5-dimethylthiazol-2-yl)2,5diphenyltetrazolium bromide (MTT; SigmaAldrich). In summary, $5 \times 10^{3}$ human unrestricted somatic stem cells were seeded on the PHB nanofibrous mats. For analysis, MTT $(20 \mu \mathrm{L}, 2.5$ $\mathrm{mg} / \mathrm{mL}$ ) was added to each well, and the plates were returned to standard tissue incubator conditions for another 4 hours at $37{ }^{\circ} \mathrm{C}$. The culture media was then removed and the cells were solubilized in $100 \mathrm{~mL}$ of dimethyl sulfoxide (DMSO). The absorbance of the solution was recorded at a wavelength of $570 \mathrm{~nm}$ using a RAYTO microplate reader. For electron microscopic investigations, the cells $(0.5 \mathrm{~mL})$ were seeded into each well of 24-well culture plates at an initial density of $4 \times 10^{5}$ cells per $\mathrm{mL}$ covered with nanofibrous mats. The cells suspension was exposed to these substrates at $37{ }^{\circ} \mathrm{C}$ in a humidified atmosphere of $95 \%$ air $/ 5 \% \mathrm{CO}_{2}$ in an incubator for 48 hours and washed twice with Hank's Balanced Salt Solution to remove unattached cells. The cultured mats with cells were washed with PBS. They were then fixed with $2.5 \%$ glutaraldehyde at $4{ }^{\circ} \mathrm{C}$ for 2 hours. The samples were dehydrated by alcohols, and kept with tetraoxide osmium vapors at $4{ }^{\circ} \mathrm{C}$ for 2 hours. Then, the samples were kept in desiccator, coated with gold, and investigated by an SEM (Cambridge Stereoscan, S-360).

\section{Anti-bacterial test}

Anti-bacterial testing is used for measuring the efficiency of fabricated mats in killing Gram-positive and Gram-negative bacteria. Hence, the anti-bacterial activity of PHB nanofibrous mats was tested against model microbial species, including Staphylococcus aureus (as Gram-positive bacteria) and Escherichia coli (as Gram-negative bacteria), by the following method [37]. First, mats were cut into $1 \times 1 \mathrm{~cm}^{2}$ and sterilized by ultraviolet radiation (the sterilization time was 10 min). Next, $5 \mathrm{~mL}$ of growth media (moolerhilton) for each bacterial species was taken in sample contained tube. The tubes were then seeded with $1 \mathrm{~mL}$ fresh culture of bacterial strains and incubated in a shaking incubator at $37{ }^{\circ} \mathrm{C}$ and for 48 hours. The turbidity of the medium was measured at $610 \mathrm{~nm}$ wavelength after 48 hours of incubation by a spectrophotometer (DU530; Beckman; Fullerton, CA, USA) and the numbers of survived bacteria were calculated by calibration curve.

\section{Results and Discussion}

SEM images of PHB/Cur 1\%, and PHB/Cur 3\% nanofibers, using different concentrations of curcumin are shown in Figure 1. To fabricate smooth and uniform nanofibers, various factors including curcumin content, polymer concentration, and electrospinning parameters were investigated. The smooth and homologous nanofibers are clearly shown in Fig. 1(a) and (b). PHB nanofibers had an average diameter of $700 \mathrm{~nm}$. However, the average diameter of the PHB/ Cur $1 \%$, and $\mathrm{PHB} / \mathrm{Cur} 3 \%$ nanofibers increased to $1-2$ $\mu \mathrm{m}$ (Fig. 1(c) and (d)), and 2-4 $\mu \mathrm{m}$, respectively (Fig. $1(e)$ and (f)) with the addition of curcumin. When curcumin was added to PHB solution, the viscosity of the solution increased which might have caused an increase in fiber diameter.

The mechanical properties of unloaded and loaded nanofibers are summarized in Table 1. PHB nanofibrous sample displayed total elastic modulus of $1.89 \mathrm{MPa}$ with an elongation of $23 \%$, and the stress strength of this sample was $0.45 \mathrm{MPa}$. Mechanical properties of the nanofibrous samples were changed with addition of curcumin in the polymer. The yield stress reduced dramatically by increasing the curcumin percentage from 1 to $3 \%$, however, the percent of elongation increased from $69 \%$ to $93 \%$. It was observed a decrease in yield stress of the polymer with the addition of curcumin up to $3 \%$, however, the elongation increased by 3 times the standard sample. Consequently, the addition of curcumin to the polymer has improved flexibility.

The release of curcumin with different percentages at specified time intervals is shown in Fig. 2. A burst release for each of the two samples was observed in the first 6 hours, and curcumin was released quickly. High doses of drug release were about $37 \%$ and $46 \%$ for curcumin $1 \%$ and $3 \%$, respectively. Then, drug release rate was reduced, and sustained release of curcumin occurred practically. Almost half of the drug was released in the first 72 hours, although this amount was about $46 \%$ and $59 \%$ for the curcumin $1 \%$ and $3 \%$, 

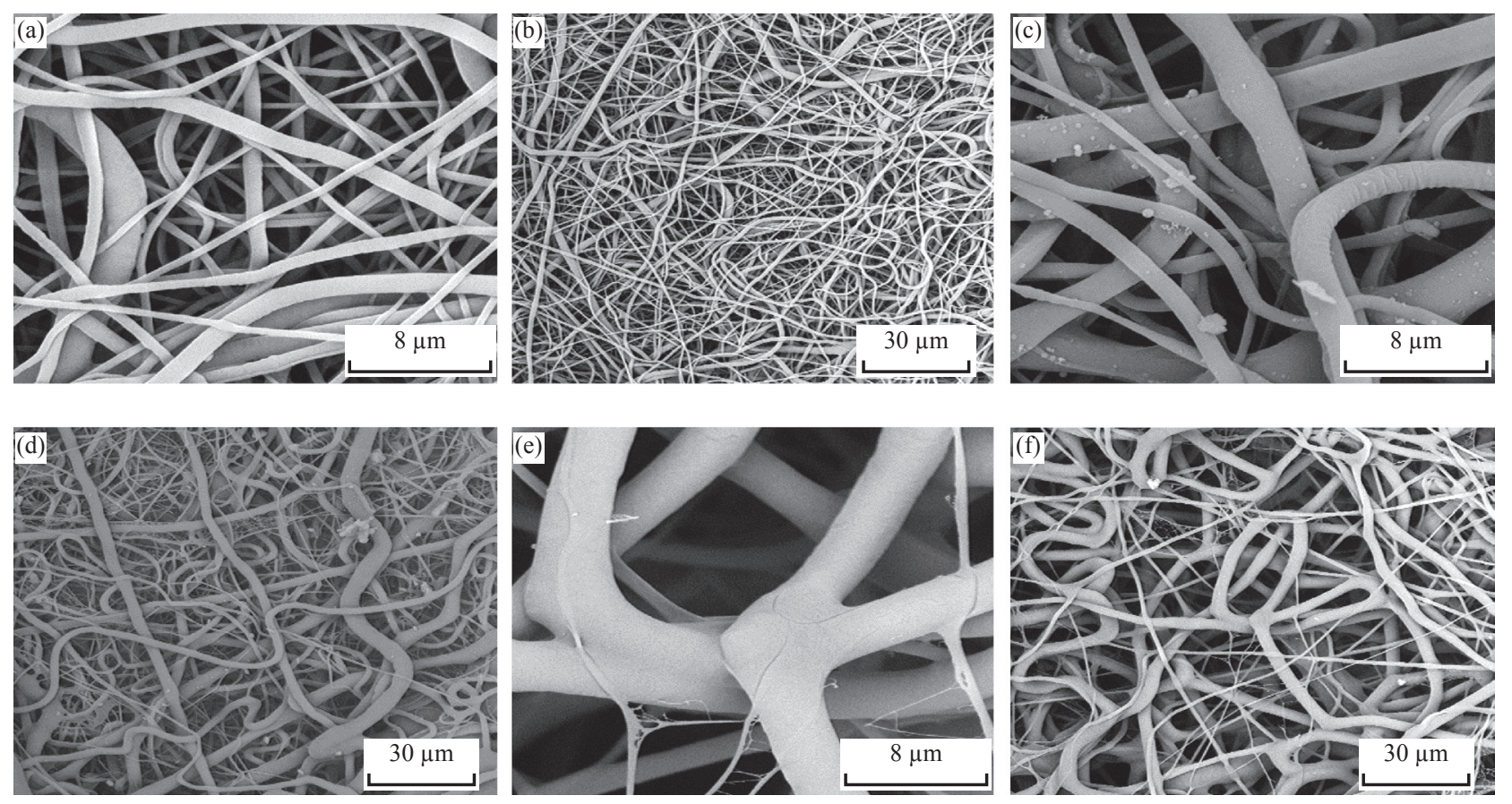

Fig. 1 SEM images of curcumin-loaded nanofibers. (a) and (b) Unloaded PHB nanofibers; (c) and (d) loaded PHB nanofibers with curcumin 1\%; and (e) and (f) loaded PHB nanofibers with curcumin 3\%. (Magnification: 1000 and $2000 \times$ ).

Table 1 The mechanical properties of loaded and unloaded nanofibers with curcumin

\begin{tabular}{cccc}
\hline Samples & Elastic modulus (MPa) & Yield stress (MPa) & Elongation (\%) \\
\hline PHB & $1.892 \pm 0.121$ & $0.445 \pm 0.111$ & $23.538 \pm 0.124$ \\
PHB/Cur 1\% & $0.091 \pm 0.052$ & $0.063 \pm 0.005$ & $69.846 \pm 0.258$ \\
PHB/Cur 3\% & $0.006 \pm 0.002$ & $0.006 \pm 0.003$ & $93.211 \pm 0.263$ \\
\hline
\end{tabular}

Note: The data are presented as the mean values $(\mathrm{p}<0.05)$.

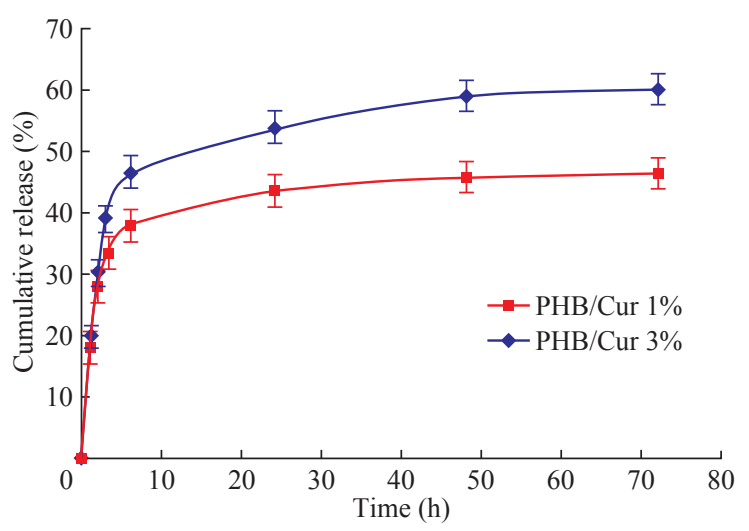

Fig. 2 The release diagram of curcumin with concentrations 1 and $3 \%$ at different times.

respectively. Moreover, drug release was increased with the degradation of PHB nanofiber. The release of curcumin in the first moments was increased with an increase in curcumin concentration in the polymeric nanofiber structure of PHB.

Cellular results from Adipose derived stem cells culture on the nanofibrous mats are shown in Fig.
3 and 4. The MTT assay results demonstrated good bioavailability or metabolic activity for samples with lower curcumin in nanofibrous mats (Fig. 3). With the increase of curcumin, cell viability did change significantly. As shown in Fig. 4, scanning electron microscopy images revealed appropriate adhesion of stem cells in contact with nanofibers surfaces. The cell adhesion also decreased with the increase in the amount of curcumin concentration.

The anti-bacterial test was used for measuring the efficiency of PHB nanofibrous mats in curcumin release and evaluating their activity to kill microorganisms. Two bacteria of S. Aureus (Grampositive) and E. coli (Gram-negative) were cultured on the manufactured electrospun mats. After 48 hours, the survived bacteria remaining on the culture were counted. The percentages of reduction of bacteria after 48 hours exposure against different mats are shown in Fig. 5(a) and (b). As can be seen, mats indicated the same bacterial activity against both Gram-negative and Gram-positive bacteria. Moreover, the mats with 3\% 


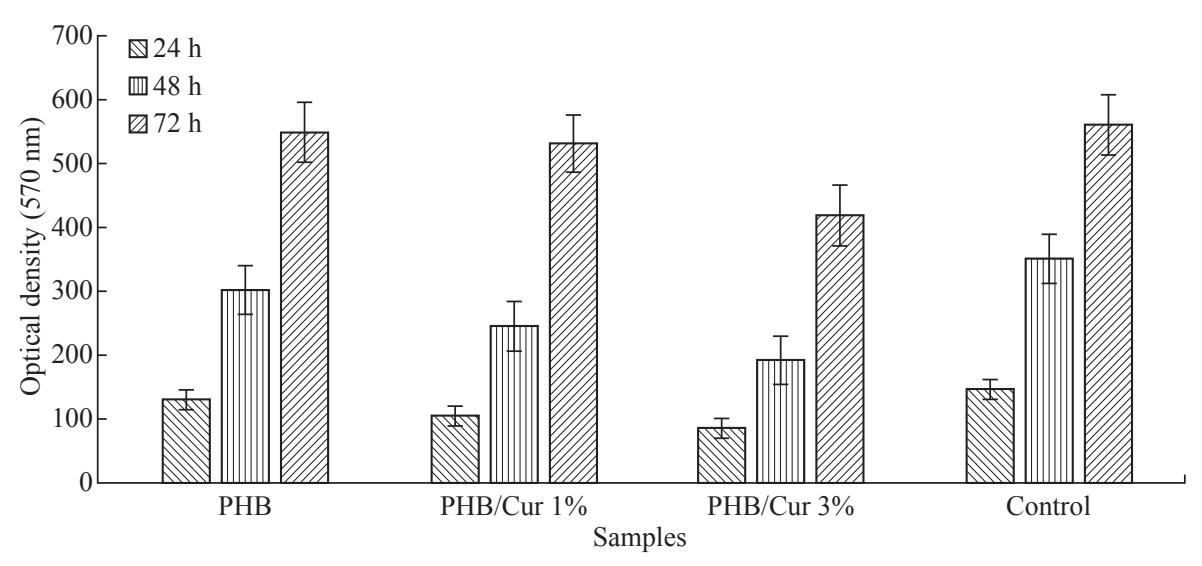

Fig. 3 Results of MTT Assay for the unloaded PHB nanofibers, Loaded PHB nanofibers with curcumin 1\%, and 3\%, and control (TCPS: Tissue culture polystyrene).
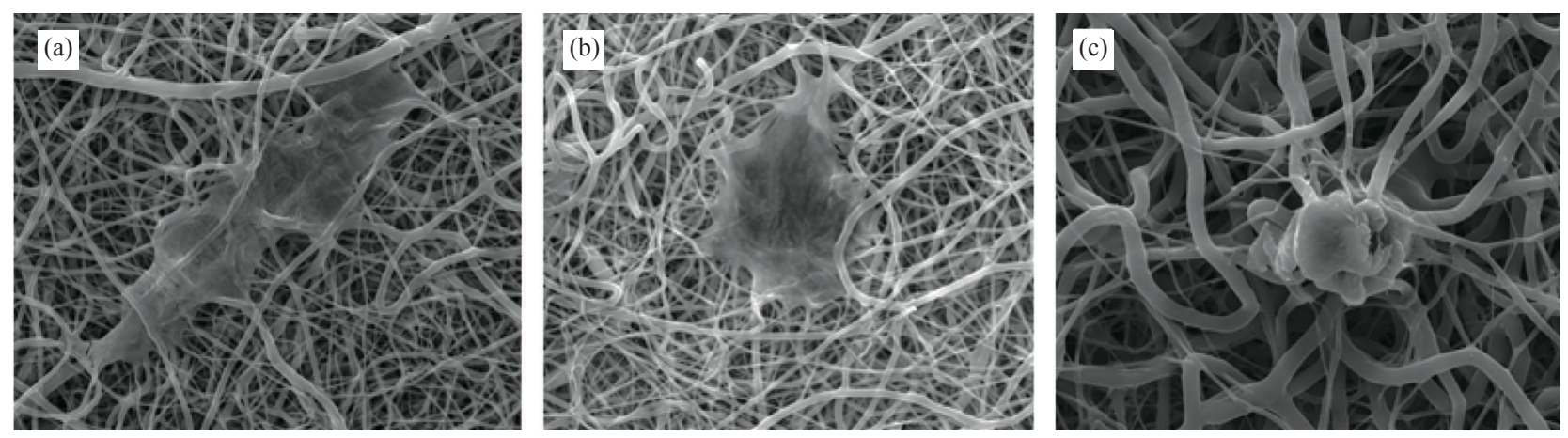

Fig. 4 SEM images of ADSCs adhesion on curcumin-loaded nanofibers. (a) Unloaded PHB nanofibers; (b) loaded PHB nanofibers with curcumin 1\%; and (c) loaded PHB nanofibers with curcumin 3\%. (Magnification: $2000 \times$ ).
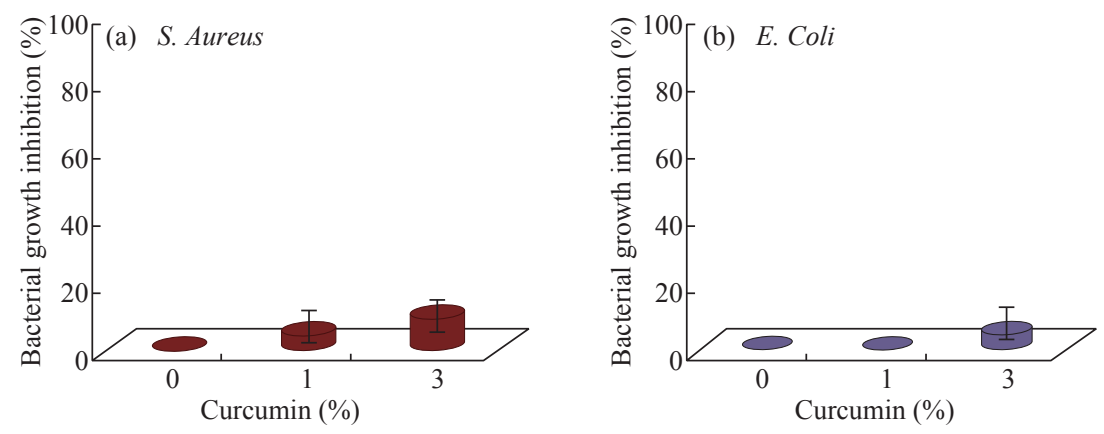

Fig. 5 Anti-bacterial properties for different CU\% mats: (a) Staphylococcus Aureus and (b) Escherichia coli.

curcumin revealed better anti-bacterial properties.

In this work, PHB polymer was used as a biodegradable and biocompatible material with curcumin which possesses anti-inflammatory properties, anticoagulant, antibacterial, antiseptic, antimutation, anti-cancer, and antioxidant effects [38]. The biodegradable PHB polymer with nanofibrous structure was used to improve its release performance. Dimethylformamide and chloroform were used as an electrolytic solution. Many studies have examined the effect of different electrospinning parameters on the morphology of fibers and fiber diameter $[37,39$,
40]. The node-free morphology was obtained with the polymer concentration of $15 \% \mathrm{w} / \mathrm{v}$ and adjustment of electrical parameters including $18 \mathrm{kV}$ voltage, $13 \mathrm{~cm}$ distance, and the feeding rate of $1 \mathrm{~mL} / \mathrm{h}$. According to electron microscope images, the diameter of fiber was increased from 600 to $800 \mathrm{~nm}$ to $1-2$ micrometers for curcumin $1 \%$ and about 4 microns for curcumin 3\% with the addition of curcumin to polymeric structure of PHB. These results could be due to increased viscosity of samples with an increase in drug concentration. The overall morphology of the nanofibers was not changed significantly by curcumin composition. But, the fiber 
diameter of the samples containing drug was increased [41]. The polymeric elongation percentage for curcumin $1 \%$ was doubled compared to the unloaded sample, and for the samples containing curcumin 3\% was tripled in comparison to the unloaded sample. It might be because of the presence of curcumin as a low molecular weight softener [35]. As shown by release profile of curcumin, $37 \%$ and $46 \%$ of burst release were identified, for nanofibers containing curcumin $1 \%$ and $3 \%$ respectively, in the first 6 hours of release. After that, the rate of release was reduced and release of curcumin was sustained. This prolonged release of curcumin would be beneficial to wound regeneration and repair process over an extended period of time. The maximum release of curcumin was observed in the polymeric sample containing curcumin 3\%. The large surface area of nanofibers and the high curcumin content are the main reasons for it. Curcumin is a hydrophobic compound and has poor water solubility. According to previous studies, only high amounts of curcumin showed toxic effects (less than 50\% of cell survival) [42]. The results showed that cell viability and survival was decreased by increasing the amount of curcumin in nanofibers. Therefore, the unloaded polymeric sample was better than the curcumin-loaded polymeric samples. There were significant changes between the three samples. Moreover, as it can be seen in SEM images, cells containing curcumin 3\% on nanofibers showed less adhesion and flattening in comparison to unloaded nanofibers and $1 \%$ curcumin. This can be due to increasing of curcumin concentration on the surface [15].

\section{Conclusions}

In summary, PHB nanofibers containing curcumin were designed and fabricated using electrospinning technique and their biological, morphological, and mechanical properties were investigated. Morphological results indicated that with increasing curcumin, fiber diameter increased significantly. The flexibility of the polymers increased significantly according to mechanical results, especially the elongation percentage of nanofibers containing curcumin. Also, in-vitro drug release study showed the appropriate rate of release for curcumin. In addition, samples with lower curcumin exhibited better cytotoxicity and cell adhesion also decreased with increasing curcumin. Due to the good properties of curcumin, this composition has the potential to be used in wound healing.

\section{Conflict of Interests}

The authors declare that no competing interest exists.

\section{References}

[1] A.G. Mikos, G. Sarakinos, M.D. Lyman, et al., Prevascularization of porous biodegradable polymers. Biotechnol Bioeng, 1993, 42: 716-723.

[2] J.L. Monaco, W.T. Lawrence, Acute wound healing: An overview. Clin Plast Surg, 2003, 30: 1-12.

[3] S.M. Choi, D. Singh, A. Kumar, et al., Porous threedimensional PVA/gelatin sponge for skin tissue engineering. Int J Polym Mater Polym Biomater, 2013, 62: 384-389.

[4] W. Zhang, P. Wang, Y. Wang, et al., Development of a cross-linked polysaccharide of ligusticum wallichii-squid skin collagen scaffold fabrication and property studies for tissue-engineering applications. Int J Polym Mater Polym Biomater, 2014, 63: 65-72.

[5] J.D. Hartgerink, E. Beniash, and S.I. Stupp, Peptideamphiphile nanofibers: A versatile scaffold for the preparation of self-assembling materials. Proc Natl Acad Sci, 2002, 99: 5133-5138.

[6] E. Biazar, S. Heidari-Keshel, Chitosan-cross-linked nanofibrous PHBV nerve guide for rat sciatic nerve regeneration across a defect bridge. ASAIO J, 2013, 59: 651-659.

[7] E. Biazar, S. Heidari-Keshel, A nanofibrous PHBV tube with Schwann cell as artificial nerve graft contributing to Rat sciatic nerve regeneration across a $30-\mathrm{mm}$ defect bridge. Cell Commun Adhes, 2013, 20: 41-49.

[8] H. Bahrami, S. Heidari-Keshel, A.J. Chari, et al., Human unrestricted somatic stem cells loaded in nanofibrous PCL scaffold and their healing effect on skin defects. Artif Cell Nanomed, 2016, 44: 1556-1560.

[9] H. Hosseinkazemi, E. Biazar, S. Bonakdar, et al., Modification of PCL electrospun nanofibrous mat with Calendula officinalis extract for improved interaction with cells. Int J Polym Mater Polym Biomater, 2015, 64: 459464.

[10] M. Sahebalzamani, E. Biazar, M. Shahrezaei, et al., Surface modification of PHBV nanofibrous mat by laminin protein and its cellular study. Int J Polym Mater Polym Biomater, 2015, 64: 149-154.

[11] M. Sahebalzamani, E. Biazar, Modification of polycaprolactone nanofibrous mat by laminin protein and its cellular study. J Biomater Tissue Eng, 2014, 4: 423429.

[12] E. Biazar, S. Heidari-Keshel, and M. Pouya, Efficacy of nanofibrous conduits in repair of long-segment sciatic nerve defects. Neural Regen Res, 2013, 8: 2501-2509.

[13] E. Biazar, A. Baradaran-Rafii, S. Heidari-Keshel, et al., Oriented nanofibrous silk as a natural scaffold for ocular epithelial regeneration. J Biomater Sci-Polym E, 2015, 26: $1139-1151$

[14] A. Baradaran-Rafii, E. Biazar, and S. Heidari-Keshel, Cellular response of limbal stem cells on PHBV/gelatin nanofibrous scaffold for ocular epithelial regeneration. Int J Polym Mater Polym Biomater, 2015, 64: 879-887.

[15] E. Biazar, S.H. Keshel, The healing effect of stem cells loaded in nanofibrous scaffolds on full thickness skin defects. J Biomed Nanotechnol, 2013, 9(9): 1471-1482. 
[16] E. Biazar, S. Heidari-Keshel, and M. Pouya, Nanofibrous nerve conduits for repair of 30-mm-long sciatic nerve defects. Neural Regen Res, 2013, 8: 2266-2274.

[17] A. Baradaran-Rafii, E. Biazar, and S. Heidari-Keshel, Cellular response of stem cells on nanofibrous scaffold for ocular surface bioengineering. ASAIO J, 2015, 61: 605612.

[18] A. Baradaran-Rafii, E. Biazar, and S. Heidari-Keshel, Cellular response of limbal stem cells on polycaprolactone nanofibrous scaffolds for ocular epithelial regeneration. Curr Eye Res., 2016, 41: 326-333.

[19] A.D. Metcalfe, M.W. Ferguson, Tissue engineering of replacement skin: The crossroads of biomaterials, wound healing, embryonic development, stem cells and regeneration. J R Soc Interface, 2007, 4: 413-437.

[20] I.V. Yannas, Synthesis of tissues and organs. Chembiochem, 2004, 5: 26-39.

[21] N.T. Dai, M.R. Williamson, N. Khammo, et al., Composite cell support membranes based on collagen and polycaprolactone for tissue engineering of skin. Biomaterials, 2004, 25: 4263-4271.

[22] W.S. Yang, H.W. Roh, W.K. Lee, et al., Evaluation of functions and tissue compatibility of poly (D, L-lacticco-glycolic acid) seeded with human dermal fibroblasts. $J$ Biomater Sci Polym Ed, 2006, 17: 151-162.

[23] E. Biazar, Polyhydroxyalkanoates as potential biomaterials for neural tissue regeneration. Int $J$ Polym Mater Polym Biomater, 2014, 63: 898-908.

[24] R. Zeinali, E. Biazar, S. Heidari-Keshel, et al., Regeneration of full-thickness skin defects using umbilical cord blood stem cells loaded into modified porous scaffolds. ASAIO J, 2014, 60: 106-114.

[25] E. Biazar, S. Heidari-Keshel, A. Sahebalzamani, et al., The healing effect of unrestricted somatic stem cells loaded in nanofibrous poly hydroxybutyrate-cohydroxyvalerate scaffold on full-thickness skin defects. $J$ Biomater Tissue Eng, 2014, 4: 20-27.

[26] S. Heidari-Keshel, E. Biazar, and T.M. Rezaei, The healing effect of unrestricted somatic stem cells loaded in collagen-modified nanofibrous PHBV scaffold on fullthickness skin defects. Artif Cell Nanomed B, 2014, 42: 210-216.

[27] E. Biazar, Application of polymeric nanofibers in medical designs, part I: Skin and eye. Int J Polym Mater Polym Biomater, 2017, 66: 521-531.

[28] E. Biazar, Application of polymeric nanofibers in soft tissues regeneration. Polym Adv Technol, 2016, 27: 14041412.

[29] E. Biazar, Application of polymeric nanofibers in medical designs, part II: Neural and cardiovascular tissues. Int $J$ Polym Mater Polym Biomater, 2016, 65: 957-970.

[30] J.G. Merrell, S.W. McLaughlin, L. Tie, et al., Curcuminloaded poly ( $\varepsilon$-caprolactone) nanofibres: Diabetic wound dressing with anti-oxidant and anti-inflammatory properties. Clin Exp Pharmacol Physiol, 2009, 36: 1149-
1156.

[31] R. Motterlini, R. Foresti, R. Bassi, et al., Curcumin, an antioxidant and anti-inflammatory agent, induces heme oxygenase- 1 and protects endothelial cells against oxidative stress. Free Radic Biol Med, 2000, 28: 13031312.

[32] G.D. Venkatasubbu, T. Anusuya, Investigation on Curcumin nanocomposite for wound dressing. Int J Biol Macromol, 2017, 98: 366-378.

[33] V.V.S.R. Karri, G. Kuppusamy, S.V. Talluri, et al., Curcumin loaded chitosan nanoparticles impregnated into collagen-alginate scaffolds for diabetic wound healing. Int J Biol Macromol, 2016, 93: 1519-1529.

[34] M. Ranjbar-Mohammadi, S.H. Bahrami, Electrospun curcumin loaded poly ( $\varepsilon$-caprolactone)/gum tragacanth nanofibers for biomedical application. Int J Biol Macromol, 2016, 84: 448-456.

[35] G. Mutlu, S. Calamak, K. Ulubayram, et al., Curcuminloaded electrospun PHBV nanofibers as potential wounddressing material. J Drug Deliv Sci Tec, 2018, 43: 185193.

[36] G. Kögler, S. Sensken, J.A. Airey, et al., A new human somatic stem cell from placental cord blood with intrinsic pluripotent differentiation potential. J Exp Med, 2004, 200: 123-135.

[37] S.M. Saeed, H. Mirzadeh, M. Zandi, et al., Designing and fabrication of curcumin loaded PCL/PVA multilayer nanofibrous electrospun structures as active wound dressing. Prog Biomater. 2017; 6: 39-48.

[38] G. Liang, S. Yang, H. Zhou, et al., Synthesis, crystal structure and anti-inflammatory properties of curcumin analogues. Eur J Med Chem, 2009, 44: 915-919.

[39] C.T. Laurencin, L.S. Nair, Nanotechnology and tissue engineering: The scaffold. Boco Raton: CRC Press, 2008.

[40] A. Doustgani, E. Vasheghani-Farahani, M. Soleimani, et al., Optimizing the mechanical properties of electrospun polycaprolactone and nanohydroxyapatite composite nanofibers. Compos Part B-Eng, 2012, 43: 1830-1836.

[41] C. Meechaisue, R. Dubin, P. Supaphol, et al., Electrospun mat of tyrosine-derived polycarbonate fibers for potential use as tissue scaffolding material. J Biomat Sci-Polym E, 2006, 17(9): 1039-1056.

[42] A. Scharstuhl, H. Mutsaers, S. Pennings, et al., Curcumininduced fibroblast apoptosis and in vitro wound contraction are regulated by antioxidants and heme oxygenase: Implications for scar formation. $J$ Cell Mol Med, 2009, 13: 712-725.

Copyright(C) Reyhaneh Ghavami L, Esmaeil Biazar, Arezoo Sodagar Taleghani, and Saeed Heidari Keshel,. This is an open-access article distributed under the terms of the Creative Commons Attribution License, which permits unrestricted use, distribution, and reproduction in any medium, provided the original author and source are credited. 